\title{
Don Quijote y Calisto Elói: intervencionistas extemporáneos
}

\author{
Macarena Cuiñas GómeZ*
}

\begin{abstract}
Resumen
Este trabajo estudia la comparación del comportamiento de dos personajes literarios ante un conflicto moral: uno en la España del siglo XVII y otro en el Portugal del XIX. Cómo intervienen en el conflicto, las consecuencias que provocan y cómo lo cuenta el narrador de cada historia.
\end{abstract}

Palabras clave: Don Quijote; Calisto Elói de Barbuda; Quijote; A Queda dum Anjo; Cervantes; Camilo Castelo Branco; narrador; literatura comparada.

Title: Don Quixote and Calisto Elói: Interventionist Untimely

\begin{abstract}
This paper examines the comparison of the behaviour of two literary characters facing a moral conflict: one in the seventeenth-century in Spain and the other one in the nineteenthcentury in Portugal. How they get involved in the conflict, the consequences that they cause and how it is told by the narrator of each story.
\end{abstract}

Keywords: Don Quijote; Calisto Elói de Barbuda; Quixote; A Queda dum Anjo; Cervantes; Camilo Castelo Branco; Narrator; Comparative Literature.

Cómo citar este artículo / Citation

Cuiñas Gómez, Macarena. 2020. «Don Quijote y Calisto Elói: intervencionistas extemporáneos». Anales Cervantinos 52: 367-377, https://doi.org/10.3989/anacervantinos.2020.015.

* Universidade Católica Portuguesa (UCP Braga). macarenacg@yahoo.es / ORCID iD: https:// orcid.org/0000-0002-6040-8900. 
El estudio del comparatismo abarca la expresión literaria de autores de diferentes lugares, culturas, lenguas y épocas ${ }^{1}$. Tanto más interesante resulta confrontar la producción literaria de varios países durante un mismo periodo de tiempo, cuanto lo es situar un texto frente a su referente original. Incluso cuando existe una distancia de siglos entre ellos, con referencias contemporáneas evidentemente distintas y diferencias en las culturas de origen.

El propósito de mi trabajo actual se encuadra en el análisis de la recepción que un escritor portugués del siglo XIX hace del personaje Quijote: la reescritura camiliana del quijotismo colocado frente a un dilema moral en una novela ( $A$ queda dum anjo) de un tiempo y lugar concretos.

Tengo que empezar por señalar que existe una clara deuda literaria entre el destacado novelista decimonónico portugués Camilo Castelo Branco y el gran Miguel de Cervantes, ya investigada, pero que es necesario recordar aquí para la correcta exposición de mi trabajo.

Camilo se relaciona con la obra de Cervantes desde dos puntos de vista diferentes: como investigador y como literato. A la primera vertiente responde un artículo de su autoría sobre la relación entre la biografía de Miguel de Cervantes y la de Manuel de Sousa Coutinho, ambas personas cautivas en Argel al mismo tiempo. Para ilustrar su estudio, cita fragmentos del Persiles que él mismo traslada al portugués. Dentro de esta faceta de traductor de Cervantes le ofrecen terminar el trabajo comenzado por el vizconde de Castilho al respecto del Quijote, pero él lo recusa por falta de tiempo e interés (Abreu 1994, 253-259).

Como escritor de ficción, publica en 1848 una narración breve titulada Cavaleiro Andante do século 19 que presenta a un personaje deudor, no del caballero de la Triste Figura, sino de las dinastías literarias caballerescas españolas y europeas anteriores a él. A este texto le siguen novelas en las que son abundantes las referencias al escritor español y sus personajes, sobre todo a don Quijote, tratado muchas veces como un alter ego del propio Cervantes, en las facetas del loco y del poeta enamorado. Así, No Bom Jesus do Monte (1864), en la que Camilo se identifica con Cervantes, Memórias d'além da campa d'um juiz eleito (1856), Aventuras dum surdo (1857), A sereia (1865), A Queda dum Anjo (1866), O senhor do Paço de Ninães (1867), O sangue (1868), Gracejos que matam (1875) y O primeiro de janeiro (1879). Y no se trata solamente de influencias en la construcción de determinados personajes camilianos, sino también de ciertas técnicas literarias, sin restar originalidad a la escritura de Camilo Castelo Branco. Podríamos citar como ejemplos cervantinos: el empleo de la parodia al tratar los géneros literarios; la ironía crítica que Camilo aplica a algunos de sus personajes y a la materia narrativa; o el interés camiliano por la influencia y relación estrecha que se establece entre la literatura y la vida ${ }^{2}$.

2. Cfr. Reis y Pires 1993, 193, 194, 199. 
Para este trabajo, parto de una premisa indudable, ya señalada por grandes cervantistas y camilianos $^{3}$ : la filiación quijotesca del protagonista de $A$ queda dum anjo (1866), Calisto Elói de Barbuda. Este aplica a su vida y a su profesión, la política, las enseñanzas aprendidas en la lectura de los clásicos (historia, filosofía, moral, genealogía, etc.). Y me apoyo en esta base para profundizar en un elemento interesante relativo a la capacidad de ambos personajes anacrónicos para "desfacer entuertos"4, la manera en la que lo hacen, las consecuencias que sus intervenciones provocan a su alrededor y cómo se comportan los narradores de las dos historias. Sin olvidar, por supuesto, los orígenes de ambos: la España de principios del siglo XVII y el Portugal de la segunda mitad del siglo XIX. Los dos reaccionan ante diferentes diatribas morales propias de su tiempo y lugar.

Acompañamos a don Quijote en sus aventuras de caballero andante, en su vida útil y gloriosa inventada por él. Como lectores, nos situamos en un plano de realidad que nosotros conocemos como ficción literaria. Dentro de ese plano de realidad para el personaje de don Quijote se suceden situaciones que son ficticias, esto es, producto de la imaginación del propio don Quijote (como los molinos de viento por gigantes, por ejemplo) o situaciones elaboradas, inventadas para él por sus amigos (como el caballero de los espejos, por ejemplo); y otras que son reales, aquellas que todos los demás también pueden ver, escuchar, etc., y que también responden a personajes igualmente existentes en la ficción literaria ${ }^{5}$.

A estos últimos pertenece Andrés, el pobre muchacho que Juan Haldudo azota en el capítulo IV de la parte I del Quijote (1605). Cuando el recién armado caballero don Quijote de la Mancha sale de la venta feliz:

La del alba sería cuando don Quijote salió de la venta, tan contento, tan gallardo, tan alborozado por verse ya armado caballero, que el gozo le reventaba por las cinchas del caballo. Mas, viniéndole a la memoria los consejos de su huésped cerca de las prevenciones tan necesarias que había de llevar consigo, especial la de los dineros y camisas, determinó volver a su casa y acomodarse de todo, y de un escudero, haciendo cuenta de recebir a un labrador vecino suyo, que era pobre y con hijos, pero muy a propósito para el oficio escuderil de la caballería. Con este pensamiento guió a Rocinante hacia su aldea, el cual, casi conociendo la querencia, con tanta gana comenzó a caminar, que parecía que no ponía los pies en el suelo (Cervantes 1998, 62).

3. Cfr. Maria Fernanda de Abreu (1994) y antes de ella Manuel Laranjeira, Túlio Ramires Ferro, Jacinto do Prado Coelho, Eduardo Lourenço, Óscar Lopes, entre otros. Todos ellos citados en Abreu (1994, 307). En la misma línea de estudios cfr. Abreu (2004 y 2013).

4. Se refiere a este hecho, con respecto a Calisto Elói, el narrador de A queda dum anjo al inicio del capítulo XII: «Santa audácia! Bizarra índole de antigo cavaleiro, que abriga no peito a generosidade com que os heróis dos Lobeiras, Barros e Morais se lançavam às aventurosas lides, no intento de corrigir vícios e endireitar as tortuosidades da humana maldade» (Castelo 2001, 73)

5. Para estas cuestiones $c f r$. Riley (1990, 68-69). 
Feliz y pensando en regresar a la aldea para proveerse de lo necesario para sus aventuras, sobre todo de un escudero, escucha los gritos de un muchacho en el bosque. Este tipo de situaciones narrativas, las voces que atraen al héroe a adentrarse en espacios naturales desconocidos, son muy propias de la novela de la época. Don Quijote se deja guiar por los sonidos hasta que se encuentra al chico atado a un árbol, desnudo de cintura para arriba y azotado por otro hombre. Don Quijote lo identifica con un caballero y le reta a batirse ante la cobardía que está cometiendo. Este labrador y ganadero le cuenta que el muchacho es su criado y la razón de su castigo y de que no le pague es que este le pierde ganado. Don Quijote le reta a desatarle y pagarle. El labrador lo desata y el chico le dice que le debe nueve meses de soldada. Hecha la cuenta por don Quijote, el labrador dice que no lleva dinero encima y que el muchacho debe ir con él para pagarle. Don Quijote queda conforme, pero Andrés no porque teme más palos y no cree a su amo. Don Quijote le insta a confiar, prometiéndole que si no sucede todo como han acordado, él volverá y arreglará de nuevo la situación. Andrés le persuade de que aquel hombre no es caballero andante, pero don Quijote no le cree y se marcha satisfecho porque el labrador se lo ha jurado y el juramento era garantía absoluta de cumplimiento. Cuando ya no los ve, el labrador vuelve a atar al chico y le pega más fuerte $y$, por supuesto, no le paga.

Don Quijote tiene ante sus ojos una situación real que interpreta desde su inocencia anacrónica de caballero andante medieval, garante de unos valores férreos basados en el cumplimiento de las promesas y el honor. Fundamentos estos que se resquebrajan en la España que ve decaer su imperio áureo. Cree inocentemente en la palabra de un hombre cruel y este se burla de él, aunque él no sea capaz de verlo. Le dice «sabed que yo soy el valeroso don Quijote de la Mancha, el desfacedor de agravios y sin razones» (Cervantes 1998, 66). Y frente a esto y a su actuación llega la burla de Juan Haldudo a Andrés mientras le propina una paliza: «-Llamad, señor Andrés, ahora -decía el labrador- al desfacedor de agravios, veréis cómo no desface aquéste. Aunque creo que no está acabado de hacer, porque me viene gana de desollaros vivo, como vos temíades» (Cervantes 1998, 66).

El personaje de Juan Haldudo se califica y construye a través de sus acciones, pero también por sus características nominativas y sociales. Su apellido, Haldudo, es un adjetivo muy significativo: 'taimado, hipócrita'. Y su rango social es el del labrador (o ganadero) rico. En la España del XVII, esta clase pugnaba contra la del hidalgo empobrecido, representada en esta novela por el protagonista Quijote. El cual, cuando Andrés le advierte que Haldudo no es caballero, le responde que no importa el linaje sino «que cada uno es hijo de sus obras» (Cervantes 1998, 65). Estas palabras son producto del pensamiento humanista de don Quijote, pero están cargadas de ironía narrativa por cuanto las obras de Haldudo no son buenas. Así que el narratario/ lector hace una doble lectura de las palabras quijotescas y les otorga una dimensión satírica más profunda. Y esto ocurre a espaldas de don Quijote, que no es consciente de la amplitud crítica de su afirmación. Efectivamente, el 
personaje Haldudo se sitúa en un lugar social concreto a través de sus actos, que no es el de caballero ni nada similar en rango.

La víctima, Andrés, es doblemente castigado por la intervención del bondadoso don Quijote: primero, porque Haldudo le pega de nuevo cuando este se va, y más fuerte por causa de la humillación que siente; y segundo, porque durante un instante alberga la esperanza de no sufrir más el dolor corporal y de recuperar su dinero. Ninguna de las dos cosas sucede finalmente, así que a su desgracia se suma la frustración de una posible solución.

El narrador cuenta la historia tal y como la vive don Quijote y relata lo que sucede cuando este se va de la escena y también cómo se siente ajeno a la realidad paralela: «Y desta manera deshizo el agravio el valeroso don Quijote; el cual, contentísimo de lo sucedido, pareciéndole que había dado felicísimo y alto principio a sus caballerías, con gran satisfación de sí mismo iba caminando hacia su aldea» (Cervantes 1998, 67). Feliz y perfecto caballero que todo lo bueno que hace lo ofrece a su dama Dulcinea del Toboso.

Pero el narrador también desvela la continuación de la historia unos capítulos más adelante, en el XXXI (I Parte). Mientras don Quijote y Sancho se encuentran con Cardenio y Dorotea en una fuente junto a una venta, pasa Andrés, que reconoce al hidalgo, se abraza a él y llora. Don Quijote cuenta a los demás su historia y la narra perfectamente, tal cual fue contada por el narrador del Quijote en el capítulo IV. A continuación, Andrés expone la realidad del final de la historia, lo que el lector ya conoce, pero don Quijote no. Aprovecha Andrés para culparle de su desgracia:

\begin{abstract}
De todo lo cual tiene vuestra merced la culpa; porque si se fuera su camino adelante y no viniera donde no le llamaban, ni se entremetiera en negocios ajenos, mi amo se contentara con darme una o dos docenas de azotes, y luego me soltara y pagara cuanto me debía. Mas como vuestra merced le deshonró tan sin propósito, y le dijo tantas villanías, encendiósele la cólera, y como no la pudo vengar en vuestra merced, cuando se vio solo descargó sobre mí el nublado, de modo que me parece que no seré más hombre en toda mi vida (Cervantes 1998, 366).
\end{abstract}

Don Quijote reconoce que no tenía que haberse ido y quiere ensillar su caballo dispuesto a reparar el agravio. Pero Dorotea le recuerda que no puede atender a más empresa que a la suya hasta que esta acabe, por lo que don Quijote emplaza a Andrés para más adelante. De nuevo, don Quijote da esperanzas a Andrés y se las quita o pospone, pero a diferencia de la primera vez, Andrés ya no le cree, no tiene fe, solamente es realista y pide algo de comer que Sancho le ofrece, y maldice a don Quijote y a la caballería andante:

-Por amor de Dios, señor caballero andante, que si otra vez me encontrare, aunque vea que me hacen pedazos, no me socorra ni ayude, sino déjeme con mi desgracia; que no será tanta, que no sea mayor la que me vendrá de su ayuda de vuestra merced, a quien Dios maldiga, y a todos cuantos caballeros andantes han nacido en el mundo (Cervantes 1998, 367). 
Y huye corriendo. El narrador interviene con su voz solamente en este momento para aludir al hecho de que don Quijote se queda muy avergonzado y los demás intentan no reírse por no humillarle más. Antes, la historia ha sido contada a través de los personajes, sus diálogos y acciones, sin intervenciones ni valoraciones del narrador. Se muestran las diferentes perspectivas de la historia ${ }^{6}$, esto es, las versiones de cada personaje, que contrastan y provocan la parodia; pero es una burla tierna, que muestra la inocencia del protagonista.

Juan Haldudo, rico labrador, sale indemne, mientras que Andrés siente la injusticia y la crueldad del mundo y ha perdido la fe en el ser humano, es una víctima, y don Quijote se siente mal por el resultado de su actuación, pero mantiene su fe en la ley de la caballería. No parece haber aprendido nada de las consecuencias de su intervención como incipiente caballero, porque no está capacitado para entender correctamente la realidad. A pesar de que siente vergüenza, asume estas consecuencias como situaciones habituales y no pretende modificar su patrón de comportamiento. Sin duda, Andrés es el que más ha perdido en el encuentro entre ambos.

Frente a otras muchas intervenciones de don Quijote en situaciones que él interpreta incorrectamente, como la procesión funeraria (capítulo 19, primera parte) que confunde con la Santa Compaña y decide combatir contra ella, o el famoso encuentro con los peligrosos galeotes (capítulo 22, primera parte), a los cuales libera erróneamente; este episodio resulta más doloroso porque la víctima, Andrés, es más vulnerable y débil. El bachiller Alonso López, uno de los integrantes del cortejo fúnebre, también queda malherido, pero es un adulto que discute y contrasta su opinión y parecer con don Quijote. Y los galeotes, con Ginés de Pasamonte a la cabeza, son delincuentes que se ven favorecidos por la intervención inexplicable de un loco. Frente a otros, Andrés es el personaje más dañado por la confusión del hidalgo manchego.

Pero ¿qué ocurre con nuestro héroe camiliano y quijotesco Calisto Elói en una intervención parecida? Antes de poder contestar a esta pregunta resulta clave comentar brevemente el carácter de este personaje de Camilo Castelo Branco y el argumento de la novela $A$ queda dum anjo (1866).

El poeta Calisto Elói de Barbuda se presenta como un hidalgo de Tras-osmontes, austero, conservador, anacrónico, amante de las leyes antiguas (no vigentes), miguelista ${ }^{7}$, que se expresa en un léxico arcaizante y muestra un aspecto extravagante al utilizar prendas ya antiguas para su época. En cuanto

6. Vid. Riley (1990) y Montero Reguera (2007).

7. La historiografía portuguesa llama miguelistas a los seguidores del movimiento llamado miguelismo integrado por todos aquellos que lucharon por la legitimidad del ex infante don Miguel de Bragança en la línea de sucesión al trono portugués. Más tarde fundaron el Partido legitimista o Partido Realista. Eran partidarios del absolutismo en oposición al liberalismo constitucional. Miguel I (Queluz, 1802- Wertheim, 1866) fue rey de Portugal y Algarve entre 1828 y 1834, y pretendiente al trono portugués desde 1834 a 1866. Era el tercer hijo varón del rey don João VI y de doña Carlota Joaquina de España y hermano del rey Pedro IV de Portugal, conocido como el emperador Pedro I de Brasil. 
al amor romántico, se presenta como un hombre indiferente al mismo pero casado por convención social. Provoca, en fin, burlas y risas al resultar un personaje ridículo en toda su extensión.

Este hidalgo, que ostenta el mayorazgo da Agra de Freimas (Miranda), es elegido por sus vecinos diputado en las Cortes, lo cual transforma su vida completamente. Pasa de llevar una vida centrada, en primer lugar, en la lectura de los clásicos de historia, filosofía y política y, en segundo lugar, en sus tierras, bien ayudado por su mujer, Teodora, una aldeana muy trabajadora; a instalarse en Lisboa para desempeñar su cargo político solamente acompañado de sus amados libros. En la capital descubrirá la vida social, totalmente desconocida para él, y se relacionará con importantes personalidades con las que llega a establecer fuertes lazos de amistad, como es el caso del juez Sarmento. Y allí se irá produciendo en él una transformación a todos los niveles. En un momento determinado de la historia, llevado por sus convicciones y autoridad moral, el Calisto Elói de la que podríamos llamar primera parte de A Queda dum anjo, esto es, el verdadera y puramente quijotesco ${ }^{8}$, media en una situación de adulterio que se desarrolla en los capítulos 11, 12 y 13, principalmente.

En ellos se narra la intervención de Calisto Elói en el matrimonio de doña Catarina Sarmento, hija del juez y mujer adúltera, y don Duarte de Malafaia, a instancias del padre de ella. Calisto Elói se haya en posesión de la verdad moral, entre otras cosas porque nadie le lleva la contraria. Se muestra muy impertinente con Catarina, al ser muy directo en su acusación de adulterio con don Bruno de Mascarenhas, y con modales más propios de zonas rurales que de la capital: «-Mas -interrogou airada e rubra de despeito a dama- que ousadia a de V. Ex ${ }^{a}$ falar assim a uma senhora que apenas conhece!... Olhe que essas liberdades de província não se usam cá em Lisboa» (Castelo Branco 2001, 70) ${ }^{9}$.

Pero si resulta agresivo y maleducado para Catarina, es un "ángel" para su padre y para Mascarenhas, aunque por motivos diferentes. Para el primero es el protector de su honor, el que intenta reparar la afrenta moral hecha por su hija. Para el segundo es el que le hace ver (sin querer) el futuro que le espera junto a Catarina: una vez separada de su marido, viviría con ella y sus cinco hijos. Nada de esto lo conoce Calisto Elói, solamente lo deduce el lector de la situación relatada y lo confirma gracias al narrador tras la promesa de viaje a Francia de Mascarenhas: «D. Bruno cumpriu a promessa com tanta pontualidade como o faria um sujeito de menos fidalgos brios, se lhe dissessem: "Afasta-te, se não queres o encargo de amparar uma família, cujo esteio estás quebrando"» (Castelo Branco 2001, 77).

8. A partir del capítulo XIV llega la caída de Calisto Elói que traiciona sus convicciones morales por el amor adúltero, no correspondido, hacia Adelaide. En este punto deja de ser personaje quijotesco, ya que el de Cervantes se mantiene siempre fiel a sus principios hasta su muerte.

9. Para la elaboración de este trabajo se han consultado tres ediciones más de A Queda dum Anjo: Castelo Branco (1984, 1986 y 2011). 
De nuevo, el mismo narrador desvela el relato de la partida de Mascarenhas contada por Adelaide a su hermana Catarina tras enterarse ella por una carta de su pretendiente Vasco da Cunha:

Pessoas que o viram a bordo referiram-lhe que o sujeito, perguntado acerca dos amores de Catarina Malafaia, respondera fatuamente que se ia escapando a um aguaceiro de escândalos, com que ele não queria brincar, porque a mulher, entusiasta e apaixonada mais que o necessário, seria capaz de o fazer assumir as funções de marido não canónico (Castelo Branco 2001, 80).

El resultado de la intervención de Calisto Elói es desigual para los diferentes personajes. Él mismo se siente honesto, heroico, cargado de la más alta moral, satisfecho de su comportamiento. Los mismos sentimientos embargan a Sarmento: «Com que delícias de alma contemplava ele a restaurada ventura daqueles casados, e o júbilo do desembargador! E os agradecimentos do ancião, que bem lhe faziam ao peito honrado!» (Castelo Branco 2001, 81).

Para Catarina todo ha sido muy diferente: cuando su amante la abandona por culpa de la intervención de un extraño, siente despecho y rabia. Pero sabe que la única salida honrosa que le queda es resignarse y aceptar su situación de mujer casada y madre. Así que se reconcilia con su marido entre remordimientos y lágrimas más o menos verdaderas. En este caso, el narrador omnisciente interviene irónica y directamente con dos comentarios de importancia:

\footnotetext{
Ora, eu não tenho a caridade de crer nos remorsos de D. Catarina; mas piamente acredito que a mulher se estava sentindo mais amiga do marido, fineza que ele devia agradecer-lhe com as suas mais melífluas carícias. (Castelo Branco 2001, 80).

É-me pequeno o peito para o prazer que sinto, relatando este caso, que é único dos meus apontamentos, em igualdade de circunstâncias. Aínda há gente boa e de muitíssima virtude; isto é verdade (Castelo Branco 2001, 81).
}

El fuerte sarcasmo del narrador establece una crítica feroz a los comportamientos íntimos y sociales de los matrimonios de la burguesía de su tiempo: todo falsedad y falta de amor sincero.

Por otro lado, ya hemos visto que Mascarenhas siente alivio por haberse zafado de un futuro que no deseaba y que no veía venir. Por lo tanto, frente al sentimiento negativo que se produce en Catarina, contrasta el positivo del amante Mascarenhas. Y Calisto Elói solamente ve una realidad: la que parte de su convicción moral y le lleva a pensar que lo que ha hecho y el modo empleado para ello ha sido correcto y además era necesario. Pero ignora la verdadera opinión que suscita en los demás su actuación (excepto en el caso del juez Sarmento, que es positiva y sincera). Los demás personajes sí que ven la realidad tal cual es (cada uno a su manera, como el marido, Duarte Malafaia, que tal vez no quiere ver...), al igual que el lector, siempre ayudado por el narrador. Este, omnisciente, totalmente subjetivo, que critica, valora, ironiza y ridiculiza el comportamiento del protagonista. 
Por lo tanto, Calisto Elói termina su intervención satisfecho, reafirmado en su proceder, nadie le hace ver la realidad, nadie le contradice, por el contrario, el juez Sarmento, alto cargo jurídico, le apoya. Tiene a su favor las profundas y antiguas convicciones morales y religiosas de la monarquía conservadora, de un sistema político-social que desde hace una década está desapareciendo en Portugal por la llegada de la Regeneração que trae consigo la crítica anticlerical y antimonárquica y que camina hacia el republicanismo y el liberalismo más radical ${ }^{10}$. El propio personaje de Calisto Elói se transformará de tradicionalista (puesto que es un hidalgo transmontano anclado en el inicio del siglo XIX) a feroz liberal en lo político y en lo personal, arrastrado por las nuevas corrientes morales de la capital lisboeta; tanto que acabará conviviendo con otra mujer, abandonando a la propia. Se convertirá, por lo tanto, en todo aquello que le resultaba moralmente intolerable y que finalmente asume con total normalidad en una suerte de hipocresía social que le hace perder la memoria del Calisto Elói de antaño: el pueblerino cargado de autoridad moral. Es un personaje al que le mueve la ambición, la avaricia, el afán por destacar en la política y la sociedad. Aspiraciones, por otro lado, perfectamente propias de su contexto en el siglo XIX europeo. Su transformación, de anacrónico pero buena persona al inicio de la novela y hasta el capítulo XIV, hasta el hombre corrupto moral y socialmente en el que se convierte por causa del poder, se encuadra en el contexto político portugués decimonónico: de legitimista migueliano (amante de valores y leyes pasadas) a liberal (sin valores ni normas morales). En este sentido, puede establecerse un paralelismo entre la España del inicio del XVII y el Portugal de mediados del XIX: ambos países ven desaparecer el mundo tal y como lo conocieron y transformarse en otro cambiante e incierto.

Si volvemos a la comparación de los dos personajes, veremos que Calisto Elói es diferente en su lectura del conflicto a don Quijote, que conoce la consecuencia de sus actos por el protagonista, Andrés, y aunque no le ayuda más, siente vergüenza. Calisto Elói se muestra interesado, ambicioso, con intención de ascender socialmente ganándose el favor del juez Sarmento, sin pensar en las consecuencias personales para los implicados en el conflicto. Actúa de manera egoísta y se cree superior a los demás. No conoce todas las versiones de la historia y de la resolución de la misma, pero es que no le interesan. Solo quiere el propio beneficio. Es un quijote desquijotizado por su propia ambición y falta de valores simbólicos y caballerescos. No parece posible para Camilo Castelo Branco ser un idealista en la turbulencia moral y política de la Lisboa de mediados del XIX. La corrupción alcanza hasta al que parecía incorruptible. La ironía camiliana es ácida y melancólica comparada con la crítica, pero suave, ironía cervantina. Frente a la inocencia y ternura que desprende el personaje de don Quijote, el de Calisto Elói resulta soberbio y ridículo, más ridículo que el propio "loco" don Quijote porque no ve, ni reconoce, ni admite otra verdad que no sea la suya. La ceguera mental

10. Cfr. Bonifácio (2002) y Barreiros (1998). 
de Calisto Elói le vuelve antipático, un anti ejemplo de conducta, aunque él pretende ser todo lo contrario. No así don Quijote: extemporáneo, anacrónico, ridículo, loco, objeto de burla, pero idealista y utópico, como la esencia del ser humano.

Cabría preguntarse si la intervención moral de uno u otro personaje ha resultado eficaz. La respuesta para nuestro héroe español y barroco es clara: no, su intervención en el conflicto Andrés-Juan Haldudo no ha sido correcta, ha favorecido al fuerte y cruel y desprotegido al débil, al indefenso niño ${ }^{11}$. ¿Y ha sido eficaz la intervención de Calisto Elói de Barbuda? Para todos menos para una: Catarina, precisamente también la más débil y desprotegida, dada su condición de mujer casada decimonónica europea. Sus sentimientos, deseos, y planteamientos vitales hacia un futuro se ven truncados por la intervención externa de Calisto Elói. Es el único personaje que sale dañado y contrariado en su libertad (ya vimos que el amante Mascarenhas resulta favorecido con este giro de los acontecimientos que le libra de un futuro familiar no deseado).

Don Quijote no puede combatir los males morales de su alrededor porque su juicio no le permite distinguirlos correctamente. Por el contrario, Calisto Elói sí que puede, pero solamente para restablecer un equilibrio social, basado en las apariencias, que parece necesario en la sociedad burguesa portuguesa de su tiempo. Ambas sociedades de tiempos diferentes y países distintos se encuentran igualmente corruptas. Don Quijote no cede jamás a esta corrupción, aunque sea desde su enajenada visión del mundo, pero Calisto Elói sucumbe y se deja arrastrar por sus más bajas pasiones traicionando el idealismo y la moralidad y cambiándola por la apariencia y la hipocresía. Así que este personaje camiliano es de clara filiación quijotesca y cervantina, pero está atravesado por la ironía cruel de su inventor, Camilo Castelo Branco, que lo utiliza para criticar fuertemente la sociedad portuguesa de su tiempo ${ }^{12}$. Lo aleja de su ejemplarizante modelo y el contraste que supone esta renuncia a sus principios morales ayuda a Camilo a construir una sátira más fuerte.

El personaje don Quijote, en todo su esplendor humano, pervive en el portugués Calisto Elói más pueril e inocente, el anjo que acaba por caer.

\section{BiBLIOGRAFÍA CITADA}

Abreu, Maria Fernanda de. 1994. Cervantes no romantismo português. Lisboa: Imprensa Universitaria, Editorial Estampa.

Abreu, María Fernanda de. 2004. «Cervantes en Portugal». En Peregrinamente peregrinos, V CINDAC, vol. 1, 3-16. Lisboa: Fundação Calouste Gulbenkian.

11. Cfr. Francolí (1980).

12. Cfr. Alves (2014) acerca de la "aparente" defensa de los valores burgueses en las novelas de Camilo Castelo Branco. 
Abreu, María Fernanda de. 2013. «1943. Don Quijote sebastianizado. En un lugar de Europa, que el autor quiso poner Tristiânia». Anales Cervantinos 45: 341-354. https:// doi.org/10.3989/anacervantinos.2013.014.

Alves Moysés, Tatiana de Fátima. 2014. «Considerações acerca da moral na fícção camiliana». Recorte 11 (1): 1-12.

Barreiros, António José. 1998. Historia de la literatura portuguesa. 2 Séculos XIX-XX. Braga: Bezerra Editora.

Bonifácio, M. Fátima. 2002. O século XIX portugués. Lisboa: ICS (Instituto de Ciências Sociais da Universidade de Lisboa).

Castelo Branco, Camilo. 1984. A queda dum anjo, introd. María de Santa Cruz. Lisboa: Biblioteca Ulisseia de autores portugueses.

Castelo Branco, Camilo. 1986. A queda dum anjo, ed. Francisco Lyon de Castro. Sintra: Europa-América.

Castelo Branco, Camilo. 2001. A queda dum anjo, prefacio Ernesto Rodrígues. Oporto: Caixotim edições.

Castelo Branco, Camilo. 2011. A queda dum anjo, prefacio António Sousa Homem. Lisboa: Bertrand editora.

Cervantes, Miguel de. 1998. Don Quijote de la Mancha, ed. Francisco Rico. Barcelona: Instituto Cervantes, Crítica, 2 vols.

Francolí, Eduardo. 1980. «El idealismo moral de Don Quijote». En Actas del Sexto Congreso Internacional de Hispanistas, coords. Evelyn Rugg y Alan M. Gordon, 276-280. Toronto: University of Toronto.

Llovet, Jordi, Robert Caner, Nora Catelli, Antoni Martí y David Viñas. 2005. Teoría literaria y literatura comparada. Barcelona: Ariel.

Montero Reguera, José. 2007. Miguel de Cervantes. Una literatura para el entretenimiento. Madrid: Montesinos.

Reis, Carlos y María da Natividade Pires. 1993. História Crítica da Literatura Portugue$s a$, vol. 5 (O Romantismo), 185-242. Lisboa: Editorial Verbo.

Riley, Edward C. 1990. Introducción al Quijote. Barcelona: Crítica.

Recibido: 8 de octubre de 2019

Aceptado: 9 de junio de 2020 
